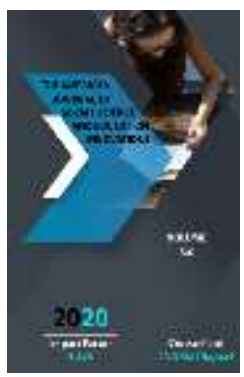

\title{
Transformation Of Values In The Social Ideal System Of A Person
}

\author{
Ulugbek Azimov
}

Researcher Of Fergana Polytechnic Institute, Uzbekistan

Journal Website: http://usajournalshub.c om/index,php/tajssei

\section{ABSTRACT}

This article examines about the influence of the value system on the emergence of a social ideal as a result of the synthesis of a value goal with social reality in the process of socialization of the individual. The article also examines the impact of social and political values on the formation of a social ideal within the social mentality.

\section{KEYWORDS}

Individual, society, socialization, mentality, social mentality, value, social ideal, political values, social values.

\section{INTRODUCTION}

The spiritual and cultural processes taking place in the world play an important role in shaping the sense of appreciation of the existence of young people, their material and spiritual benefits. It is important to form and develop the axiological consciousness in young people in all respects, to lose the nihilistic worldview, which is its dialectical side.
Axiological consciousness is a special form of social consciousness that reflects in a unique way based on a sense of appreciation for the universe, reality, and life. The axiological form of the worldview formed on its basis includes such a valuable approach, axiological attitude, axiological assessment. With the addition of elements of axiological worldview to the general system of worldview, the sense of 
appreciation, value attitude and axiological assessment of social subjects in relation to reality becomes more pronounced. At the same time, axiological principles are manifested as moral criteria that regulate people's attitudes to reality, their interactions with each other. They are also seen in the interests and goals of people in carrying out their activities. In the structure of the social mentality, along with social perceptions, political values can also be distinguished. As an alternative to the concept of value in modern foreign languages, "value" in English, "valuer" in French, "wert" in German, and they mean not only "value" but also "value" [1].

\section{MATERIALS AND METHODS}

It is noted in modern encyclopedic literature that the concept of value first appeared in Kant's work, when the thinker contrasted the realm of spirituality (freedom) with the realm of nature (necessity). "Values do not exist in themselves, they only matter: they are demands on the will, on the goal". [2]. At the same time, the concept of value was introduced into circulation by F. Lottse, who believes that value exists only in its significance for the subject.

Axiology as an independent cultural and philosophical science emerged in the midnineteenth century in the context of a philosophical analysis of human life.

Several types of value theory have been formed. Neo-Kantianism described values as ideal beings in the form of representatives of the Baden (Freiburg) school (V. Windelband, G. Rickert) and representatives of the Marburg school (P. Natorp, E. Cassirer and others). The transcendental subject was the carrier of this ideal. Personalist ontologism (M. Scheller) sought to prove the objective nature of values. Naturalistic psychology (A. Maynong, J. Dewey, etc.) approached values as objective factors of reality that could be empirically recorded. Cultural-historical relativism (W. Diltey, O. Spengler, A. Toynbee) tried to prove the existence of a large number of equal value systems. The sociological concept of values, consisting of $M$. Weber, F. Znanetsky's "understanding sociology", the school of structural and functional analysis (T. Parsons, E. Schilz, K. Klakhon and others), solved the problem of values in the framework of social theory.

These types of value theory differentiated their approaches according to the modality of the existence of values, which appealed to either the individual, or the superiority of values over the individual or nature. In Western philosophy, interest in the problem of values has been particularly strong in the last decade of the twentieth century.

In recent years, scholars have published a large number of monographs devoted to the study of general and specific aspects of the theory of value.

In particular, A. Edel distinguishes three directions of axiological research: idealistic, naturalistic and pragmatic research. $T$. Lyubimova distinguishes three types of value theory, but according to a special principle: "theoretical sociological”, "metaphysical", "negative-critical". The historian of German axiology A. Messer has four directions: "phenomenological (M. Scheller)", "idealistic (G. Rickert)"; "Idealistic-realistic (G. Munsterberg)" and "realistic (A. Stern)". M. Kissel distinguishes five types of theory of values: "naturalistic psychology", "transcendentalism", "personalistic ontology", "cultural-historical relativism" and "sociology". Werkmeister distinguishes even more approaches to the development of the theory of values: "utilitarian-economic", "emotional-intuitive", "metaphysical", "personalistic", "psychological-genetic", "phenomenological”, "instrumentalist", "aesthetic", "Humanistic", “relativistic", “empirical-cognitive", "linguistic" [3]. 
In the literature published during the Soviet period, the problem of values was approached from the point of view of Marxist doctrine. In 1982, V. Sagatovsky described values as "general stable perceptions based on the subject's previous experience of preferred benefits and optimal ways to enjoy them". V.Yadov distinguished between "normsvalues", "ideal-values", "goal-values" and "means-values" [4].

\section{RESEARCH METHODOLOGY}

In the course of the research were used scientifically-philosophical principles and methods such as systematics, theoreticaldeductive conclusions, analysis and synthesis, history and logic, hermeneutic analysis, inheritance, universalism and nationality, comparative analysis.

\section{ANALYSIS AND RESULTS}

M.S. Kagan distinguishes particularly common interpretations of the concept of values in Western philosophy. For example, A. Maslow describes values as specific principles inherent in every living thing. The author called his concept a "naturalistic science of human values". In doing so, he said, "just as we learn the values of ants, horses, or trees, or Martians, so we can learn the higher values or goals of man". [5] he thinks. The American philosopher R. Perry puts forward the idea in his proposed axiological theory that the concept of value is a product of the concept of interests. According to him, "interests" cover various areas of human life. Accordingly, values also acquire such qualities that they cease to be values in the literal sense of the word [6].

The study of the problem of values in the late 80 s - early 90 s of the XX century became relevant with the understanding that the changes taking place in our country are inextricably linked with the attitude of the population to values. An analysis of the literature on the theoretical problems of the study of values allows us to conclude that there are currently different approaches to defining the content of the concept of value [7].

For example, when P.S. Gurevich systematizes philosophical approaches to defining the content of the concept of value, he comes to the following conclusions. First of all, value is manifested as a symbol of a new idea that acts as a social or individual goal. Second, value acts as an expression of a subjective image or imagination. Third, value is identified with ideals and norms. Fourth, value defines a specific individual identity. P.S. Gurevich himself describes value as an individualpersonal attitude to the world that arises in accordance with knowledge and daily experience[8].

In the literature on psychology, value is interpreted as a concept that expresses objects, events and their properties, as well as abstract goals that embody social ideals. In this, three forms of value existence are distinguished.

The first is value as a social ideal. Such values can be universal and concrete-historical (patriarchy, equality, democracy). The second is a value that manifests itself in the form of objectified material as works of material and spiritual culture or human behavior, which is a concrete expression of the ideals of society in terms of values (moral, aesthetic, political, legal, etc.). The third is a value that is manifested in terms of individual life activities, which enters the psychological structure of the person as a personal value that acts as one of the sources that determine his behavior.

Each person has an individual hierarchy of personal values. These values connect the spiritual culture of society and the spiritual world of the individual. Personal values are reflected in the mind as an attitude to values and serve as an important factor in the social 
regulation of human relationships and personal behavior [9].

In this case, the values apply both as objective categories and as subjective categories [10]. However, some philosophers believe that the nature of certain values can be determined in the system of "subjectivity - objectivity". We are talking about "high" values, such as "happiness", "friendship", "love”, "freedom", "justice". These are values that have an interpersonal or interdisciplinary basis. In this case, the values, according to G.P.Vijletsov, merge with the goal and become an ideal [11].

According to M.S. Kagan, the study of values in terms of content should be based on their historical nature: the development of values is historically determined, which reinforces the importance of a historical approach to their study. "The application of the biogenetic law of E. Geckel, which is often overlooked by philosophers, that ontogeny repeats phylogeny, that is, the laws of development of the individual repeat the development of the species, is an important methodological principle of modern axiology".[12].

The literature published in recent years differs in content, including: family, spiritual, religious, national, moral, legal, political and other values[13]. There are no specific works on the content of the concept of "political values", but some political values have been studied in the process of empirical sociological research. [14].

In the encyclopedic literature, political values are defined as "goal setting, choice of means and methods of activity, a set of ideas, perceptions and corresponding sociopsychological structures (goals, models, experiences, etc.) that determine the degree of consistency of their application and implementation in current political practice. At the same time, the task of political values is to promote the unification of a social group that is part of a broader social unit; to stimulate political activity and create conditions for socio-political goals to become direct motives for participants in the political process; to facilitate the formation of standards for evaluating each specific action and its consequences; defining a hierarchy of policy goals and ways to achieve them; it is emphasized that each participant in the political process (class, party, public organization, institution, individual) is helped to aim at the rest of its elements. [15].

In our view, this interpretation of the concept of social values encompasses the social mentality in terms of content, because here socio-political values are both ideas, perceptions, goals and experiences.

M.S. Kagan's work offers a unique interpretation of social values. On the one hand, he interprets social values based on the philosophical notion that it is a struggle for power between social groups consisting of different political parties and movements. On the other hand, in describing social values, the author argues that they "emerge at the sociopsychological level of social consciousness as aspects of national behavior, class psychology, class identity common to the macrogroup, and ideologically shaped by theorists. Social values take precedence over the individual, because appropriate values are given by the individual not in his own name, but in the name of the unit to which he belongs, but these values are determined by the extent to which the individual perceives the interests and ideals of the unit to which he belongs".[16].

The importance of social values, according to M.S. Kagan, is twofold: on the one hand, they unite people and on the other hand, they create discord between them, because it strengthens the unity of any part of humanity and at the same time undermines its integrity, it can even lead to and justify military and revolutionary conflicts.

While legal values are by their nature regulatory, stabilizing, and stable, social values can be both constructive and destructive in 
nature, justifying both reactionary practices and reformist practices and revolutionary practices[17].

M.S. Kagan called a large number of people whether or not they knew each other, whether they communicated directly with each other or not unites basic socio-political values such as unifying patriotism, citizenship, national pride, party discipline. [18].

According to Rokich, value is when a person or society prefers a particular behavior or eventuality to a particular behavior or situation[19]. It should be noted that this interpretation of the concept of value fully satisfies specific socio-political researchers, because it allows the practical values to be measured not only qualitatively but also quantitatively.

In our view, social values are reflected in social norms and ideals. Social norms are certain rules that determine political behavior and political participation in a social process. The application of social norms is generally determined by the need to regulate political relations. Social norms are expressed both as conscious and logically defined rules of behavior and as unconscious rules of behavior to which means are subject.

Social norms, which acquire a certain character, regulate and coordinate the activities of political subjects of relations, regulate the various types of social relations. Institutional social norms are relatively stable, unchanging, and if they are legally enforceable, they become mandatory for all. However, this feature of social norms sometimes deprives them of flexibility, the ability to adapt themselves to a particular social situation, which weakens the effectiveness of the implementation of the regulatory function of the social norm.

Under such conditions, new, uninstitutionalized social norms may emerge that take on an acceptable character and can clearly reflect changing circumstances. Social norms are directly related to ideological systems and therefore have both a permissible feature and an acceptable feature.

Another form of expression of social values is social ideals. In the philosophical literature, the ideal is understood as the concept of perfection, its model, the highest goal of aspiration. In the words of I. Fixte, "we know that ideals cannot exist in the real world; we believe that reality should be judged only on the basis of ideals, and reality is changed by those who have the power to do so". [20].

In the literature published in recent years, the ideal is often understood as a spiritual expression of a certain norm, an image of perfection, which people try to equalize in their activities, which is different from everyday reality and has a motivating power and influence.

S. Agzamkhodjaeva gives various definitions of the concept of ideal, which can be used to describe the content of the concept of political ideal, proposed in the philosophical literature[21]. Thus, in the interpretation of Sh. Kahharova, the ideal is a form of goal setting in all spheres of social life [22]. In the interpretation of Al Yatsenko, the ideal serves as the most important general end goal of the object. It is the goal that guides the subject's socially formative conscious activity. The ultimate goal of ideal activity is the "goal of goals". According to O.G.Drobnitsky, ideals "reflect the ultimate goals of individuality and collective action, which have become a mandatory program for all".[23].

\section{CONCLUSION}

The social ideal can be described as a perfect model of reality and the highest goal of social activity. The social ideal reflects the subject's attitude toward reality.

\section{REFERENCES}

1. Kagan M.S. Philosophical theory of value. SP (b): 1997 .- S.41. 
2. Contemporary Western Philosophy. Vocabulary. - Moscow: Odyssey, 1991 .- p. 11-14.

3. V.V.Kryukov Sum of axiology. Novosibirsk: Publishing house of NSTU, 2018 .-- P.19-20.

4. Kagan M.S. Philosophical theory of value. -SP (b): 2005 - p.36-37.

5. Maslow A. On the psychology of being. Moscow: AST, 1997. - P.78.

6. Kagan M.S. Philosophical theory of value SP (b): 2005. -p.27; Perry R.B. General Theory of Value. It's meaning and basic principles, construed in terms of interest. - Cambridge: Mass, 1950. -P.68.

7. O. V. Bondarenko The world of values: the axiology of social development. - Rostovon-Don: 1998. - P.11; Agazzi E. Man as a subject of philosophy. Moscow: 1989; lyer A.J. Man as a subject of scientific research // Man and his values. - Moscow: 1988; Vijletsov G.P. Spiritual values and the fate of people // Socio-political journal, 1994. №3-6; Gurevich P.S. Man and his values. Moscow, 1988; A.G. Zdravomyslov Needs. Interests. Values. - Moscow :, 1986.

8. Gurevich P.S. Philosophy of culture. Moscow: 2014 .-- P. 127-131

9. Psychology. Vocabulary. - Moscow:1990.P. 442.

10. Philosophical Encyclopedic Dictionary. Moscow: 2001. - p. 507.

11. Vijletsov G.P. Spiritual values and the fate of people // Socio-political journal, 1994, №3-6.

12. That place. - P.61-62

13. Vyzhletsov G.P. Spiritual values and the fate of people. -Moscow: AGRAF, 2015.P. 23

14. Lapin N.I. Upgrading basic values. // Sociological research. 1996. No. 5; Tikhonova N.E. Worldview values and political process // Social sciences and modernity. 1996. No. 4; Mentality of Nations - Moscow: 1997; O. V. Bondarenko The value world of peoples: the axiology of original social development. - Rostovon-Don: 1998.
15. Political science. Encyclopedic Dictionary. Moscow: 1993. - p. 391

16. Kagan M.S. Philosophical theory of value SP (b): 2005. -P. 100

17. Kagan M.S. Philosophical theory of value SP (b): 2005. -P. 101.

18. That place. - P.100.

19. Kagan M.S. Philosophical theory of value SP (b): 2005 --P. 51

20. Philosophical Encyclopedic Dictionary. Moscow: Modern notebooks. 2001 .-- P. 169

21. Agzamkhujaeva S. Social ideal and problems of spiritual development in Uzbekistan // Fals, science. Ph.D. diss. 09.00.11 Social Philosophy. - Tashkent: National University of Uzbekistan, 2008.

22. Kahharova Sh. Global spirituality is the ideological basis of globalization. Tashkent: Tafakkur, 2009. -P.

23. Drobnitskiy O.G. Theoretical and methodological questions of the study of the ideal of social structure. Moscow: 2015. - p. 5. 